\title{
Motivation for Using ICT and Pupils with Learning Difficulties
}

\author{
https://doi.org/10.3991/ijet.v11i10.5786 \\ S. Bagon ${ }^{1}$ and J. Lepicnik Vodopivec ${ }^{2}$ \\ ${ }^{1}$ Primary School Louisa Adamica Grosuplje, Slovenia \\ ${ }^{2}$ University of Primorska, Slovenia
}

\begin{abstract}
Teachers often consider modern active teaching methods to be better suited for students who are good at learning or even for gifted students, as they assume that students with learning disabilities have underdeveloped metacognitive and social learning skills, that they require more time to grasp the techniques of the more advanced, technology aided teaching methods and that they cannot acquire additional knowledge at the same time. Our research focuses on pupils with learning disabilities, their attitude towards learning and teaching with the help of ICT and on motivation that arises from it. The study has shown that students with learning disabilities are confident enough in their computer skills that teachers may freely use modern teaching methods with them in primary school, as even those children are motivated and have a good attitude towards such teaching methods.
\end{abstract}

Index Terms-educational technology, learning disabilities, motivation.

\section{INTRODUCTION}

\section{A. Use of ICT with pupils with special needs and learning disabilities}

In teaching and education, lately more and more attention is paid to students with special educational needs, a group which also includes students with deficiencis in individual fields of learning, i.e. students with learning disabilities. There are increasing numbers of studies on the positive effects of ICT aided teaching and learning on the results and achievements of children, pupils and studnets with special needs, i.e. the blind and the visually impaired, the deaf and hearing-impaired, children with psychological development disorders, children with physical disabilities or others. We are also seeing the emergence of various studies on the effect of ICT on students with severe forms of specific learning disabilities, which are called deficiencies in specific fields of learning; however, such studies are rare. This group also includes students with critical and non-critical learning disabilities. Opara [9] summarized the findings of the US expert $\mathrm{H}$. G. Unger, who distinguishes between children with critical learning disabilities and those with non-critical ones. Children with non-critical learning disabilities have decreased abilities in non-essential skills and can still develop them with the help of counselling, correction exercises and other correction methods. Critical learning disabilities are those that hinder the child's learning (dyslexia, dysgraphia, ADHD, dyscalculia, etc.). Among the Slovene primary school population there are approximately 10 to 20 percent of children with deficiencies in individual fields of learning [9]. 2 to 10 percent of children have specific reading dis- orders and 1 do 6 percent have specific math-related disabilities [7]. And the situation elsewhere? H. D. Unger [9] says that children with critical learning problems constitute about three to ten percent of the whole child population. Since the percentage of pupils with critical and noncritical learning disabilities in our primary schools is so high, it is crucial that we study the impact of education technology on these students and on their attitude and motivation for learning with the aid of computers, especially in regard to students with non-critical learning disabilities, as this particular field is the least explored of them all.

Past studies performed on children without learning disabilities have mostly shown only positive effects of computer aided modern teaching methods. What is more, studies on children with special needs and deficiencies in individual fields of learning have shown a positive impact on their cognitive and social areas. A study by Cheng and Yea [5] revealed that a $3 \mathrm{D}$ virtual learning environment can help develop better social competences in autistic children. Whether autistic persons can suitably understand and use technology was studied by Parson, Leonard and Mitchell [12], who also discovered a positive influence of virtual environment on the development of social skills in autistic persons. In their study, Folkesson and Swalander [6] discovered that children aged 8 and 9 years who use ICT in school have better developed reading comprehension skills than those who learn only through traditional methods. They found that the primary reason for such results is the ICT's motivational role and the secondary is easier reading of written text, as large and legible letters allow the pupils to read faster and read more. Sung, Chang and Huang [17] have studied the impact of computer aided teaching strategies and environment on reading and reading comprehension skills in primary school children with different learning abilities. They found that ICT increases the motivation for reading in pupils with low reading skills, which in turn improves their reading strategies and reading comprehension. Children with learning disabilities are very attentive to visual stimuli, which is why computer aided teaching has such positive effects on their achievements [21].

Most studies on the attitude towards teaching with the aid of information technology were done among undergraduate and post-graduate students and some among secondary school students, whereby none of the studies mentioned learning disabilities and primary school pupils. A study on first year undergraduate students at one of the US universities revealed that the students have a positive attitude towards integration of educational technologies into education; however, they expressed doubts regarding 
their qualification for such learning, which requires time to acquire [4]. In that example the researchers (ibid.) studied the attitude towards integrating a number of different electronic media and sources, including e-mail, internet, Microsoft Excel and Power Point, electronic texts, video and audio sources, photographs, etc. [14] carried out a study among students in Spain, which they limited to the attitude towards the use of the Moodle virtual learning environment, which is also often used in Slovene primary school, and came to a similar conclusion: students support this type of learning, but their positive attitude is strongly based on the assurance of technical assistance. The Greek researcher Papastergiou [11] studied how pupils learn through educational computer games and noticed that this type of teaching brings better results compared to classical teaching and that the motivation to learn is higher than in classical learning. The author did not notice any differences between the sexes, despite that fact that it was initially established that males had more experience with computers. On the other hand, Shaw and Marlow [16] discovered a more positive attitude towards ICT aided learning in men. In studying the attitude towards learning with the aid of educational technology, the researchers focused on comfort, interaction with the learning process, absence of a personal note, entertainment value and comparison to traditional learning. Similarly, Vekiri and Chronaki [19] found that compared to primary school girls, primary school boys use the computer at home more frequently, have confidence in their own competences and efficiency, and a higher perception of one's own computer skills as values.

Motivation has been one of the key concepts of pedagogical psychology for a long time. It is a process that involves objectives as well as physical and mental activities [13] and on a general level encompasses various events that cause shifts and lead to appropriate measures [2]. Jarvela and Volet [20] claim that it was not before the 1980 s that motivation was transferred from laboratories to the natural learning environment and that until then studies on motivation had very little influence on the teaching process. Today motivation is crucially related to the learning process and learning achievements [20]. Boekaerts [3] emphasizes that understanding pupils' behaviour depends on both the cognitive factors like knowledge, skills and abilities, and the motivational factors, which is why motivation should always be taken into account when studying the use of ICT in the learning process. Recently researchers all over the world started studying factors that influence pupils' or students' motivation for learning and for work with the computer. In her study on motivational factors that influence e-learning, Selvi [15] found that the following factors play the greatest motivational role in learning with the aid of technology: learning process, teacher's competences, pupil participation, type of online learning environment and time management. Similar conclusions were made by Paechter, Maier and Macher [10], who found that teacher's competence in e-learning has a strong impact on pupils' satisfaction and that higher learning achievements are influenced by independence in planning and by group learning, which is categorized as a learning process by Selvi [15]. In short, the use of technology in learning plays a high motivational role. Bakar, Ayub and Tarmizi [1] confirmed that premise in regard to learning mathematics and Tüzün, Yılmaz-Soylu, Karakus, Inal and Kiz1lkaya [18] did the same for geography. How- ever, these studies have similar drawbacks as the studies of attitudes towards ICT aided learning; namely, they were also performed only on children without learning difficulties, undergraduate and postgraduate students.

In addition to pupils' attitude towards integration of educational technology into teaching and towards the motivational role that modern computer aided methods play in it, experts emphasize the importance of interaction developed among the pupils and between the pupils and the teacher, as this enables pupils to develop their social sphere while improving their cognitive abilities. Yeh and Lahman [22] studied the interactions at higher education institutions. When they studied the characteristics of the student - student interaction, they found that it is an important factor in stimulating the efficiency of e-learning and an important element for successful discussion. The majority of participants in their study mostly noted the positive effects of learning and teaching methods, e.g. a different form of teaching, exchange of thoughts, experience and ideas, accessibility from home, more time to think, etc. However, certain problems were noted due to the lack of verbal communication. In reviewing the interaction between the student and the teacher, the students expressed a desire for teacher's cooperation and constructive feedback. The authors find that the teacher plays an important role in motivating students and stimulating their participation. Similar results were achieved by McBrien and Jones [8] in South Florida, who also state that teachers motivate students to learn through ICT by encouraging them and through a good social integration of students.

With the help of computers and other educational technology (interactive whiteboard - IWB, projector, camera, $\mathrm{TV}$, etc.) we can allow pupils to participate in various learning activities, such as computer aided project work, cooperative distance learning, learning through educational computer games and computer simulations, participation in chat rooms and forums, keeping a web diary, solving interactive exercises, learning about a virtual environment, and recording video and sound clips. The most important thing about all these activities is that pupils actively participate in the educational process, guide their learning and select their activities, and that they learn how to work together and how to learn individually. By limiting the use of modern computer aided teaching and work methods for students with learning disabilities, teachers inadvertently send them information that they are underachievers in the field of technology as well, even though it is later often revealed that such assumptions are unfounded. Teachers are forgetting how ICT improves students' achievements by raising their motivation and how it can improve pupils' attitude towards learning with the help of educational technology. Pintrich and Schunk [13] find that students who are convinced of their abilities and have a desire to succeed are more ambitious and determined, and consequently more successful than those who think of themselves as underachievers who cannot succeed. It is crucial that information technology is used with all pupils, with or without learning disabilities, as equally as possible, as it affects their self-esteem and their confidence in their own abilities.

\section{OBJECTIVES}

The above mentioned studies provide sufficient evidence to convince us that the use of information technology is a crucial and welcome addition for pupils and stu- 
dents. This research, however, focuses on pupils with learning disabilities, their attitude towards learning and teaching with the help of ICT and on motivation that arises from it. The objectives of our study were:

- to identify the attitude of primary school children with learning disabilities towards the use of modern teaching technology in the learning process;

- to identify the effect of motivation in primary school children with learning disabilities on learning with the help of educational technology;

- to identify which motivational factors in ICT aided learning are the most important to pupils with learning disabilities;

- to find out if there is a connection between the frequency of ICT use in lessons and the attitude towards ICT use in the learning process and the motivation of pupils' with learning disabilities;

- to find out if there is a connection between the frequency of computer use when pupils with learning disabilities learn at home and their attitude towards the use of ICT in the learning process;

- to study the influence of confidence of pupils with learning disabilities in their computer skills in on their attitude towards and motivation to use ICT in the learning process and

- to compare the attitude, motivation, frequency of use at home and the confidence in one's own abilities among pupils with learning disabilities.

\section{METHOD}

\section{A. Participants}

The research covered 78 primary school children from two Slovene regions. All of them were affected by learning disabilities of various levels and intensities. The participant breakdown was: 42 boys $(53.8 \%)$ and 36 girls $(46.2 \%)$. Pupils were aged 11 to 15 years; 28 pupils were aged 11, 18 aged 12, 23 were aged 13, 5 were aged 14 and 3 were aged 15 years. The average pupil age was 12.2 years. There were 32 sixth-graders, 19 seventh-graders, 19 eighth-graders and 8 nine-graders.

\section{B. Materials and procedure}

The research method was quantitative empiric nonexperimental, whereby we carried out a survey about opinions, a correlation research and a comparative analysis. We gathered data through a questionnaire that was divided into five parts: basic data about the participant; questions relating to the attitude towards the use of educational technology in the learning process; questions relating to motivation and motivational factors of ICT use in teaching and learning; questions on the frequency of computer and computer related media use at home and in school and questions on the assessment of one's own ability and efficiency of computer use. The questions were posed in the form of statements with a five-level Likert scale, an assessment scale and closed answers. The questionnaire's reliability and internal consistency were tested based on the Cronbach's alpha test $(\alpha)$ with the result being $0.880(\alpha \geq 0.80)$, which means that the instrument's reliability is very good.

The employed statistical methods relied on univariate, bivariate and multivariate SPPS analyses. In the opinion survey, when we observed the attitude towards and moti- vation for the use of ICT in the learning process, we used a factor analysis. In identifying the correlation between the frequency of educational technology use at home and during lessons at school and the attitude towards and the motivation for modern learning methods, we used the Spearman's correlation coefficient. The comparative analysis between boys and girls was done with the help of the Pearson chi-square test. For basic data processing we used descriptive statistics.

\section{RESULTS}

\section{A. The attitude of primary school children with learning disabilities towards the use of modern educational technology in the learning process}

In the attitude of primary school children towards the use of modern educational technology we observed the following three factors: 1.) opinion of pupils with learning disabilities that computer aided learning is much more fun than classic teaching in the class with traditional learning methods; 2.) opinion on the frequency of computer use during lessons and 3.) the level of fun which they used to define whether the computer was used only for entertainment or for learning as well. The results have shown that pupils have a positive attitude towards the use of modern technology in the learning process, as the arithmetic mean in the first observed factor was 3.73 with a standard deviation of 1.625; in the second factor the arithmetic mean was 3.64 with a standard deviation of 1.627 and in the third factor it was 2.72 with a standard deviation of 1.520 . The highest mean value of answers is therefore present in the factor that computers should be used more often during class than they currently are. In all three statements pupils with learning disabilities came very close to the answer stating that they partially agree with the statement. Pupils who stated that computer aided learning is more fun than classic lessons were also of the opinion that computers should be used more often during class. There is a significant correlation $(\mathrm{r}=0.563 ; \mathrm{p}>0.01)$ and statistical significance between the two variables. There was no statistically significant correlation between knowledge and attitude. According to the Spearman's coefficient, there is also no statistically significant correlation between gender and the attitude towards computer aided learning. Furthermore, Pearson's chi-square test did not show any significant statistical difference between the attitude of boys and that of girls towards the use of modern educational technology in the learning process.

\section{$B$. Influence of motivation in children with learning disabilities on learning with the help of educational technology}

When studying motivation of pupils with learning disabilities for the use of modern computer aided learning technology in learning and teaching we observed three factors. In the statement that they use the computer only when the teacher requires them to, the mean answer value is 2.60 with a standard deviation of 1.606 . The arithmetic mean in the statement that if possible, students try to avoid leaning with the help of a computer is 2.46 with a standard deviation of 1.509 . In the statement that pupils only rarely stud at home with the help of the computer, arithmetic mean is 2.78 and the standard deviation 1.534. This means that the children disagreed most with the statement that they avoid computer aided learning whenever possible. In all tree cases they were the closest to the answer that they 
do not agree with the statement, so we may conclude that their motivation for learning with the help of computer technology is high. There is a positive mean relation $(r=0.288 ; \mathrm{p}<0.05)$ between students who use the computer only when the teacher expects them to and those who try to avoid learning and doing exercise with the help of the computer. Therefore students who prefer to avoid learning with the help of a computer also use the computer only then when it is required by the teacher. According to the Spearman coefficient, there is no correlation between children's gender and their motivation for computer aided learning. The correlation is very low and not statistically significant $(\mathrm{p}>0.05)$. What is more, Pearson's chi-square test did not reveal any statistically significant differences between boys' and girls' motivation for using modern technology in the learning process.

\section{The most important motivational factors for students with learning disabilities in ICT aided learning}

Factor analysis revealed that the following factors most contribute to motivation: understanding the contents; higher marks, contact with schoolmates and independent learning. It is based on the fact that their variation share was higher than 0.5 .

As seen from the table above, high motivation for computer aided learning has a strong positive correlation with the following factors: higher marks, better grasp of the contents, independence in learning, accessibility of the contents and teacher's presence. Contact with schoolmates and work in pairs or groups have the lowest correlation.

\section{Correlations between the frequency of ICT use in lessons and the attitude to ICT use in the learning process and motivation of students with learning disabilities}

When asked how often they use computers in lessons, $26.9 \%$ of pupils replied that they never use it; $30.8 \%$ of participants estimate that they use it two to three times per year; $24.4 \%$ said they learn with the help of computers two to three times per month and $16.7 \%$ of pupils responded that they use computers in every lesson. The mean value of the answers is 2.28 , meaning that the average response was that in lessons they use computers about two to three times per year, which is quite infrequent. On average, pupils stated that during lessons the most often used modern educational piece of technology was the IWB, as the arithmetic mean is the highest for this item, resulting in 2.59 with a standard deviation of 1.769 . Often the teachers also use projections of Power Point presentations, where the arithmetic mean is 2.45 and the standard deviation 1.718; and internet browsers, where the arithmetic mean is 2.45 and the standard deviation is 1.656 . In all these cases the pupils' answers came closest to the statement that the medium or the activity is seldom or even very seldom used in lessons. Furthermore, they never or very rarely learn with the help of forums, as the arithmetic mean in this statement is 1.45 with the standard deviation of 1.015 , or through computer games, where the arithmetic mean is 1.88 and the standard deviation is 1.441 . The Spearman correlation coefficient showed a mean negative correlation between the frequency of computer use in lessons and the attitude towards computer aided learning and classic teaching methods $(r=-0.225)$ and is statistically significant $(\mathrm{p}<0.05)$. This means that the less often computers are used in lessons, the less fun computer aided learning seems to children with learning disabilities compared to classic learning methods. We also established a statistically significant positive correlation between the frequency of computer use during lessons and pupils' motivation for learning through the use of modern educational technology, which relates to the statement that pupils only use computers if they are required to do so by the teacher. The correlation coefficient is $0.328(p<0,05)$, which means that the more often the teacher uses computer during lessons, the less pupils agree with the statement that they only use computers if required to do so by the teacher.

\section{E. Correlation between how often children with learning disabilities use the computer at home for learning and their attitude towards ICT use in the learning process}

The results show that on the average boys are slightly more likely to use the computer for learning at home than girls, as in boys' case the mean answer value was 2.43 with a standard deviation of 0.770 ; in girls the arithmetic mean of answers was 2.09 with a standard deviation of 0.749 . Thus both male and female pupils came closest to the answer that they use computer for learning at home two to three times per month. The breakdown looks like this: $9.5 \%$ of boys and $2.8 \%$ of girls never use the computer at home for learning, while $45.2 \%$ of boys and 58.3 $\%$ of girls use it two to three times per month; $38.1 \%$ of boys and $27.8 \%$ of girls use it two to three times per week and $7.1 \%$ of boys and $2.8 \%$ of girls use it every time they study. However, in using computers for learning at home the difference between boys and girls with learning disabilities is statistically not significant. Spearman's correlation coefficient revealed a positive mean correlation and statistic significance $(r=0.248 ; \mathrm{p}<0.05)$ between the use of computers for learning at home and the opinion that computer aided learning is more fun than classic lessons, which means that the more often pupils use the computer at home, the more likely they are to agree with the statement that the learning process with the use of modern computer educational technology is more fun than traditional lessons. There is a positive correlation between the frequency of computer use at home and the opinion that computers should be used at school more often and a negative correlation between how often computers are used for learning at home and the statement that pupils only use computers for fun and not for learning, however, these two correlations are not statistically significant.

\section{$F$. The influence of pupils with disabilities' confidence in their own computer skills on their attitude towards and motivation for using ICT in the learning process}

On average, both girls and boys estimate that their knowledge of the Excel tool is the weakest, as the arithmetic mean in this case in boys is 2.74 with a standard deviation of 1.822; in girls the arithmetic mean is 2.29 with a standard deviation of 1.680 , which means that their most common answer was that their knowledge of this application is very poor or poor. Both boys and girls find that their knowledge of computers is best when it comes to browsing the internet, as in boys the arithmetic mean for browsing the internet is 4.57 with a standard deviation of 1.085; in girls the arithmetic mean is 4.47 with a standard deviation of 1.253. They gave the highest mark to their knowledge of e-mail, as in boys' case the mean value of answers is 4.14 with a standard deviation of 1.491 and 
in girls' the arithmetic mean is 4.36 with a standard deviation of 1.313 . Therefore, in both cases the values were closest to the answer that they are proficient in using this tool or application. There is no statistically significant difference between boys and girls in their estimate of their computer skills. The Spearman correlation coefficient showed a positive mean correlation between the frequency of online classroom use in lessons and the pupils' knowledge of online classroom use $(r=0.239 ; \mathrm{p}=0.01)$. Furthermore, there is also a positive mean correlation between the frequency of strengthening the knowledge of what they learned with the help of interactive exercises in lessons and pupils' estimation of their knowledge of online classroom use in learning $(\mathrm{r}=0.291 ; \mathrm{p}<0.05)$, a positive mean correlation between the frequency of learning with the help of computer simulations and the pupils' estimate of their skills in using the online classroom for learning $(\mathrm{r}=0.307 ; \mathrm{p}<0.05)$, a positive correlation between the pupils' knowledge of PowerPoint and the frequency of using PowerPoint projections during lessons $(\mathrm{r}=0.258$; $\mathrm{p}<0-05)$ and a positive correlation between pupils' knowledge of using the online classroom and the frequency of teaching with the help of IWB at lessons $(r=0.278$; $\mathrm{p}<0.05)$. There is a positive correlation between the computer skills and the frequency of computer use while studying at home; however, it is not statistically significant. We also could not find a statistically significant correlation between the frequency of computer use during lessons and computer skills, even though a positive correlation exists.

\section{DISCUSSION}

Children with learning disabilities have a positive attitude towards ICT use in the learning process, just like it was found for undergraduate students by Buckley et al. [14]. The difference is revealed in the expressed doubt, as Buckley et al. [14] found that students doubt in their adequate computer skills, while this study showed that most pupils do not agree with the statement that they do not have as many computer skills as the teacher expects from them. On general, all pupils with learning disabilities highly assessed their knowledge of computer applications. Sánchez and Hueros [14] also discovered a positive attitude towards the use of educational technology; however, their study also revealed that constant technical assistance is crucial to students.

Furthermore, the study showed that motivation for learning with the help of educational technology is high in pupils with learning disabilities, thus reaching the same result as the studies done by Papastergiou [11], Bakar et al. [1] and Tüzün et al. [18]. Papastergiou [11] also found that learning with the help of computer games brings better results. We cannot say the same based on our study, as we did not check this aspect, but we can definitely state that pupils believe that computer aided learning improves their understanding of what they learn and consequently, their marks. In addition, independence in learning and contact with schoolmates proved to be relevant motivational factors. It has thus become evident that to pupils with learning disabilities other motivational factors are important as well, as was established by Selvi [15], Paechter et al. [10], Yeh and Lahman [22], and McBrien and Jones [8], as their studies show that students particularly value teacher's presence and cooperative work, which were given low marks by pupils with learning disa- bilities. Similarly, as found in a study by Yeh and Lahman [22], it is important to pupils with learning disabilities that learning materials are always accessible.

In this research no statistically significant difference in attitude and motivation towards modern educational technology between boys and girls was identified. We can therefore agree with Papastergiou [11], who also did not find any differences between the sexes in their attitude towards ICT use in the learning process. On the other hand, Shaw and Marlow [16] identified a more positive attitude towards ICT aided learning in men. Maybe the explanation for such a difference could be found in the fact that their study was done over 20 years ago, in 1999, when ICT use was much less common than it is today. Additionally, no statistically significant difference was found between male and female children with learning disabilities in the frequency of computer use at home and their estimation of their own knowledge about certain computer functions, which is the opposite of what was found by Vekiri and Chronaki [19].

\section{CONCLUSION}

In conclusion, when using modern computer aided methods the teacher should disregard whether children have learning disabilities or not, as all pupils consider ICT an equally important motivation for learning and work at school and at home. Modern literature offers a number of best practice examples of ICT use in teaching, among which the following should be mentioned: online classrooms, PowerPoint presentations, electronic texts, interactive quizzes and exercises, creating audio and video clips and the use of existing ones, synchronous and asynchronous communication via e-mail, forums or chat rooms, computer aided project work, e-book design, use of IWBs, e-materials, video conferences, web page design, publishing a webzine, learning with the help of simulations and video games, keeping a web diary, etc. The study covered a relatively low number of participants and in order to obtain more reliable results it should be expanded to a broader primary school population. In the future it would also be interesting to compare the answers on ICT use at home and during lessons with students with learning disabilities, on attitude and motivation. Research results should therefore serve as an encouragement for teachers to start using modern computer aided educational technology with pupils with learning disabilities, putting them on equal footing with the more capable pupils and enabling them to acquire quality computer skills in the primary school. Past studies have mostly focused on undergraduate and postgraduate students and ICT or on children with more complex special educational needs, while using modern computer aided educational technology in primary school students with learning disabilities remained mostly unexplored, making such studies crucial for shedding light on that subject and bringing ICT aided teaching closer to pupils with learning disabilities.

\section{REFERENCES}

[1] K. A. Bakar, A. F. M. Ayub, W. S. Luan, W. S. and R. A. Tarmizi, "Exploring secondary school students' motivation using technologies in teaching and learning mathematics,"Procedia Social and Behavioral Sciences, vol. 2, pp 4650-4654, 2010. http://dx.doi.org/10.1016/j.sbspro.2010.03.744

[2] A. Bandura, "Self-Evaluative and Self-Efficacy Mechanism Governing the Motivational Effects of Goal Systems", Nebraska: Symposium on Motivation, 1990, pp 69-76. 
PAPER

\section{MOTIVATION FOR USING ICT AND PUPILS WITH LEARNING DIFFICULTIES}

[3] M. Boekaerts, "Motivation to learn", International Academy of Education, 2001.

[4] C. A. Buckley, E. Pitt, B. Norton and T. Owens, "Students' approaches to study,conceptions of learning and judgements about the value of networked technologies", Active Learning in Higher Education, vol. 11/1, pp. 55-65, 2010. http://dx.doi.org/10.1177/ 1469787409355875

[5] Y. Cheng, and J. Ye., "Exploring the social competence of students with autism spectrum conditions in a collaborative virtual learning environment - The pilot study", Computers \& Education, vol. 54, pp. 1068-1077, 2010. http://dx.doi.org/10.1016/j.comp edu.2009.10.011

[6] A. Folkesson and L. Swalander, "Self-regulated learning through writing on computers: Consequences for reading comprehension", Computers in Human Behavior, vol. 23, pp. 2488-2508, 2007. http://dx.doi.org/10.1016/j.chb.2006.04.003

[7] L. Magajna, "Specifične učne težave - prepoznavanje, razumevanje, premagovanje. In N. Kočnik Goršič in M. Kavkler, Specifične učne težave otrok in mladostnikov (pp. 15-28). Ljubljana: Svetovalni center za otroke, mladostnike in starše, 2007.

[8] L. J. McBrien and J. Jones, "Virtual spaces: Employing a synchronous online classroom to facilitate student engagement in online learning", International Review of Research in Open and Distance Learning, vol. 10/3, pp. 1-17, 2007.

[9] B. Opara, "Otroci s posebnimi potrebami v vrtcih in šolah. Vloga in naloga vrtcev in šol pri vzgoji in izobraževanju otrok s posebnimi potrebami”, Ljubljana: Centerkontura, 2009.

[10] M. Paechter, B. Maier and D. Macher, "Students' expectations of, and experiences in e-learning: Their relation to learning achievements and course satisfaction", Computers \& Education, vol. 54, pp. 222-229, 2010. http://dx.doi.org/10.1016/j.compedu.2009. 08.005

[11] M. Papastergiou, "Digital Game-Based Learning in high school Computer Science education: Impact on educational effectiveness and student motivation", Computers \& Education, vol. 52, pp. 112, 2009. http://dx.doi.org/10.1016/j.compedu.2008.06.004

[12] S. Parsons, A. Leonard, and P. Mitchell, "Virtual environments for social skills training: comments from two adolescents with autistic spectrum disorder", Computers \& Education, vol. 47, pp. 186206, 2006. http://dx.doi.org/10.1016/j.compedu.2004.10.003

[13] P. R. Pintrich and D. H. Schunk, "Motivation in Education: Theory, Research \& Applications", Englewood Cliffs, New Jersey: Prentice Hall, 1996.

[14] R. A. Sánchez, and D. Hueros, " Motivational factors that influence the acceptance of Moodle using TAM", Computers in Hu- man Behavior, vol. 26, pp. 1632-1640, 2010. http://dx.doi.org/10.1016/j.chb.2010.06.011

[15] K. Selvi, " Motivating factors in online courses", Procedia Social and Behavioral Sciences, vol. 2, pp. 819-824, 2010 http://dx.doi.org/10.1016/j.sbspro.2010.03.110

[16] G. Shaw, and N Marlow, "The role of student learning styles, gender, attitudes and perceptions on information and communication technology assisted learning", Computers \& Education, vol. 33, pp. 223-234, 1999. http://dx.doi.org/10.1016/S03601315(99)00020-2

[17] Y. Sung, K. Chang, and Y. Huan, "Improving children's reading comprehension and use of strategies through computer-based strategy training", Computers in Human Behavior, vol. 24, pp. 1552-1571, 2008. http://dx.doi.org/10.1016/j.chb.2007.05.009

[18] H. Tüzün, M. Yılmaz-Soylu, T. Karakus, Y. Inal, and G. Kizilkaya, "The effects of computer games on primary school students' achievement and motivation in geography learning", Computers \& Education, vol. 52, pp. 68-77, 2009. http://dx.doi.org/10.1016/j.compedu.2008.06.008

[19] I. Vekiri, and A. Chronaki, "Gender issues in technology use: Perceived socialsupport, computer self-efficacy and value beliefs, and computer use beyond school", Computers \& Education, vol. 51, pp. 1392-1404, 2008 http://dx.doi.org/10.1016/j.compedu. 2008.01.003

[20] S. Järvelä, "Shifting research on motivatn and cognition to an integrated aproach on learning and motivation context", In S. Volet in S. Järvelä, "Motivation in Learning Contexts: Theoretical Advances and Methodological Implications", (pp. 105-127). Amsterdam: Pargamon, 2009.

[21] L. Vera, R. Campos, G. Herrera, and C Romero, "Computer graphics applications in the education process of people with learning difficulties", Computers \& Graphics, vol. 31, pp. 649658, 2007. http://dx.doi.org/10.1016/j.cag.2007.03.003

[22] H. T. Yeh, and M. Lahman, "Pre-service teachers' perceptions of asynchronous online discussion on blackboard", The Qualitative Report, vol. 12/4, pp. 680-704, 2007.

\section{AUTHORS}

S. Bagon is $\mathrm{PhD}$ Teacer of Primary School of Louisa Adamica Grosuplje, Slovenia, spela.bagon@guest.arnes.si

J. Lepicnik Vodopivec is PhD Full Professor of Pedagogy at the Faculty of Education University of Primorska, Slovenia,jurka.lepicnik@pef.upr.si

Submitted 23 April 2016. Published as resubmitted by the authors 16 July 2016. 